\title{
TI VERDE: UMA ANÁLISE DOS PRINCIPAIS BENEFÍCIOS E PRÁTICAS UTILIZADAS PELAS ORGANIZAÇÕES
}

\author{
Guilherme Lerch Lunardi \\ gllunardi@furg.br \\ Universidade Federal do Rio Grande - Rio Grande, RS / Brasil \\ Renata Simões \\ rersimoes@yahoo.com.br \\ Universidade Federal do Rio Grande - Rio Grande, RS / Brasil \\ Ricardo Saraiva Frio \\ saraiva.frio@ibest.com.br \\ Pontifícia Universidade Católica do Rio Grande do Sul - Porto Alegre, RS / Brasil
}

\begin{abstract}
Recebido em 03/03/2012
Aprovado em 18/07/2013

Disponibilizado em 01/04/2014

Avaliado pelo sistema double blind review

Revista Eletrônica de Administração

Editor: Luís Felipe Nascimento

ISSN 1413-2311 (versão on-line)

Editada pela Escola de Administração da Universidade Federal do Rio Grande do Sul.

Periodicidade: Quadrimestral

Sistema requerido: Adobe Acrobat Reader.
\end{abstract}

\section{RESUMO}

As questões envolvendo os problemas ambientais, o esgotamento de recursos naturais não renováveis e o crescimento econômico desvinculado do desenvolvimento sustentável tornaram-se uma grande preocupação mundial nos últimos anos, o que tem levado tanto governantes quanto as sociedades civis e as próprias organizações a proporem diferentes medidas para a preservação do planeta e, consequente, sobrevivência das gerações futuras. Embora a área de TI tenha contribuído bastante para a construção desse panorama, cada vez mais, diretores e gerentes de TI têm se mostrado preocupados com o impacto ambiental proporcionado pela TI. Essa situação tem feito com que diferentes práticas venham sendo adotadas pelas organizações de modo a reduzir o desperdício e aumentar a eficiência dos processos e fenômenos relacionados à operação dos computadores - sendo comumente referidas pelos praticantes da área como iniciativas de TI Verde. Assim, objetivou-se identificar e analisar os principais benefícios e práticas de TI Verde adotados pelas organizações. A pesquisa se trata de um estudo exploratório-descritivo, cujos dados foram obtidos e analisados a partir de 202 diferentes anúncios publicados sob a forma de artigos, cases, entrevistas, notícias e sites institucionais, no período de 2006 a 2011. A análise permitiu categorizar as principais práticas e seus respectivos benefícios. Identificou-se que os principais ganhos estão associados à redução de custos, à redução de insumos, ao menor

REAd | Porto Alegre - Edição 77 - N 1 - janeiro/abril 2014 - p. 1-30 
TI Verde: uma análise dos principais benefícios e práticas utilizadas pelas organizações

consumo de energia, à melhoria da imagem institucional e à redução da emissão de gases. Dentre as práticas mais utilizadas, destacam-se a consolidação de servidores e desktops, o uso de equipamentos mais eficientes, a reciclagem de componentes e as campanhas de conscientização. Espera-se que os resultados dessa pesquisa possam estimular tanto acadêmicos, quanto praticantes, no estudo e na implementação de diferentes iniciativas de TI Verde que venham não somente tornar as organizações mais eficientes e eficazes, mas também mais comprometidas com a preservação do planeta.

Palavras-Chave: TI Verde; Sustentabilidade; Tecnologia da Informação; Práticas Verdes.

\title{
GREEN IT: AN ANALYSIS OF THE MAIN BENEFITS AND PRACTICES USED BY ORGANIZATIONS
}

\begin{abstract}
Issues regarding environmental problems, depletion of nonrenewable natural resources and economic growth disconnected to sustainable development have become a major global concern in recent years, leading governors, civil societies and organizations to propose different attitudes for preserving the planet and, consequently, the survival of future generations. Although IT has contributed a lot to build this scenario, more and more directors and managers have expressed concerns about the environmental impact provided by IT. This situation has driven organizations to adopt different practices to reduce waste and increase the efficiency of processes and phenomena related to computer operations - which have been commonly reported by practitioners as Green IT initiatives. We aim to identify and analyze the main Green IT benefits and practices adopted by organizations. The research is characterized as a descriptive-exploratory study; data were obtained and analyzed from 202 different electronic announcements published in articles, case studies, interviews, news and institutional sites from 2006-2011. The analysis allowed us to categorize the main practices and their benefits. We found that the major gains are associated with cost reduction, reduction of inputs, lower energy consumption, better corporate image and reduction of greenhouse gas. The main practices include server and desktop consolidation, more efficient equipment use, recycling of components and awareness campaigns. We hope the results of this research can stimulate both academics and practitioners in the study and implementation of different Green IT initiatives which will not only make organizations more efficient and effective but also more committed to preserving the planet.
\end{abstract}

Keywords: Green IT; Sustainability; Information Technology; Green Practices.

\section{GREEN IT: UN ANÁLISIS DE LOS PRINCIPALES BENEFICIOS Y PRÁCTICAS UTILIZADAS POR LAS ORGANIZACIONES}

\author{
RESUMEN
}

REAd | Porto Alegre - Edição 77 - N 1 - janeiro/abril 2014 - p. 1-30 
Los asuntos relacionados a los problemas del medio ambiente, el agotamiento de los recursos naturales no renovables y el crecimiento económico sin relación con el desarrollo sostenible se han convertido en una de las principales preocupaciones mundiales en los últimos años, lo que ha llevado a los gobiernos, la sociedad civil y las organizaciones a proponer diferentes medidas para la preservación del planeta $\mathrm{y}$, en consecuencia, la supervivencia de las generaciones futuras. Aunque el área de TI ha contribuido mucho para construir este escenario, cada vez más, los directores y gerentes han expresado su preocupación sobre el impacto ambiental proporcionado por la TI. Esta situación ha llevado a las organizaciones a adoptar diferentes prácticas para reducir el desperdicio y aumentar la eficiencia de los procesos y fenómenos relacionados con las operaciones del ordenador - que han sido comúnmente reportados por los practicantes como iniciativas de Green IT. Por lo tanto, objetivase en este estudio identificar y analizar los principales beneficios y prácticas de Green IT adoptadas por las organizaciones. La investigación caracterizase como un estudio exploratorio descriptivo, cuyos datos fueron obtenidos y analizados a partir de 202 anuncios publicados en forma de artículos, estudios de caso, entrevistas, noticias y sitios institucionales en el período 2006 a 2011. El análisis permitió categorizar las principales prácticas y sus beneficios. Se encontró que las principales ventajas están asociadas con la reducción de costes, reducción de insumos, el menor consumo de energía, la mejor imagen corporativa y la reducción de las emisiones de gases de efecto invernadero. Entre las prácticas que más se utilizan, aparecen la consolidación de servidores y desktops, el uso de equipos más eficientes, el reciclaje de componentes y las campañas de sensibilización. Esperase que los resultados de esta investigación puedan estimular académicos y profesionales en el estudio y la aplicación de diversas iniciativas de Green IT que no sólo harán las organizaciones más eficientes y eficaces, pero también más comprometidas con la preservación del planeta.

Palabras Clave: Green IT; Sostenibilidad; Tecnología de la Información; Prácticas Verdes.

\section{INTRODUÇÃO}

As questões envolvendo os problemas ambientais, o esgotamento de recursos naturais não renováveis e o crescimento econômico desvinculado do desenvolvimento sustentável tornaram-se uma grande preocupação mundial nos últimos anos. Em pesquisa realizada pelas Nações Unidas quanto aos assuntos dominantes no futuro, o desenvolvimento sustentável aparece como a principal preocupação identificada pelos respondentes (WATSON, BOUDREAU e CHEN, 2010). Como o relatório observa, "nunca antes a opinião mundial foi tão unida em um simples objetivo, como alcançar o desenvolvimento sustentável” (p. 23). Essa preocupação atingiu os mais diversos setores da economia, o que tem levado tanto governantes quanto as sociedades civis e as próprias organizações a proporem diferentes medidas para a preservação do planeta e, consequente sobrevivência das gerações futuras.

O crescimento dos problemas ambientais acabou por redirecionar a competitividade na década passada (VANTTINEN e PYHALTO, 2009) e as mudanças nos valores sociais e no REAd | Porto Alegre - Edição 77 - N 1 - janeiro/abril 2014 - p. 1-30 
TI Verde: uma análise dos principais benefícios e práticas utilizadas pelas organizações

desenvolvimento de novas tecnologias têm propiciado o surgimento de produtos ecologicamente corretos, onde emergem novos movimentos "verdes", tendo como principais objetivos a redução da poluição e da energia no desenvolvimento de produtos e serviços (D'SOUZA et al., 2006).

Embora o aumento contínuo do uso operacional da Tecnologia da Informação (TI) nas organizações venha provocando consequências ambientais graves, especialmente por ser apontada como um dos principais responsáveis pelo aquecimento global (tanto pela emissão de dióxido de carbono quanto pelo consumo de energia, uso e descarte de materiais), cada vez mais, diretores e gerentes de TI têm se mostrado preocupados com o impacto ambiental proporcionado pela TI (SPOSITO, 2008; MONTE, 2009c). O movimento da ecoconsciência chegou nos departamentos de tecnologia sob o nome de TI Verde, sendo direcionada principalmente pelos negócios e constituindo-se em uma das principais preocupações dos CIOs (MOLLA, 2009) sendo, desde 2008, apontada como uma das principais tendências da área (THIBODEAU, 2007; COMPUTERWORLD, 2009a; ITWEB, 2009).

Estimativas sugerem que o mercado de serviços de TI Verde deverá chegar próximo a US\$ 5 bilhões até 2013. Tais previsões apontam o papel central dos sistemas de informação, dada a sua visão interfuncional da organização e habilidade para entender, modificar e reinventar os processos de negócio para melhor suportar as práticas sustentáveis (MINES apud WATSON, BOUDREAU e CHEN, 2010), de modo a reduzir o desperdício e aumentar a eficiência dos processos e fenômenos relacionados à operação dos computadores. A TI, nesse sentido, pode ser vista sob duas óticas: uma, analisada a partir de cada estágio do ciclo de vida dos recursos tecnológicos - da manufatura ao uso e à sua alienação - que podem causar danos ambientais; e outra, utilizada para combater o impacto ambiental, seja analisando e monitorando os efeitos da emissão de dióxido de carbono e do efeito estufa, ou ainda reduzindo o consumo de água, energia e desperdício dentro da organização e nos processos da cadeia de valor (ELLIOT e BINNEY, 2008).

Kim e Ko (2010) salientam que como cada organização tem sua própria perspectiva para avaliar o ambiente de negócios, é possível que uma boa parte delas se torne ambientalmente proativa, enquanto muitas outras ainda sejam relutantes a tomarem uma abordagem mais agressiva. Uma visão mais superficial sobre esta temática sugere que as atividades ambientais podem aumentar os custos de produção por causa dos investimentos de capital e custos de operação, resultando em um relacionamento negativo entre a adoção de 
Guilherme Lerch Lunardi, Renata Simões \&Ricardo Saraiva Frio

práticas verdes e o resultado financeiro da empresa. Entretanto, diferentes artigos e pesquisas - publicadas, na sua grande maioria, em revistas comerciais - têm apontado que as mesmas atividades podem levar a um resultado financeiro positivo, através de riscos e perdas minimizadas, fuga de multas relacionadas a marcos regulatórios e, ainda, novas oportunidades em segmentos de mercado conscientes ambientalmente (LANKOSKI, 2008).

Embora essas iniciativas venham sendo aplicadas com maior frequência e intensidade pelos executivos, a TI Verde ainda é um tema de pesquisa relativamente recente, sendo pouco explorado na literatura acadêmica - comprovada por uma reconhecida falta de pesquisas publicadas na área (BROOKS, WANG e SARKER, 2010). Enquanto a opinião pública, as organizações e as áreas de Sistemas de Informação (SI) parecem unidas no reconhecimento desse problema, a comunidade acadêmica de SI se mostra amplamente ignorante quanto ao desafio do desenvolvimento sustentável, com pequenas exceções (WATSON, BOUDREAU e CHEN, 2010).

Desse modo, saber o que as organizações estão realmente fazendo com relação à sustentabilidade na área de TI, bem como identificar os principais benefícios das práticas adotadas, pode auxiliar tanto acadêmicos quanto praticantes a uma maior compreensão da importância dessa temática às organizações. Assim, objetivou-se neste estudo identificar as principais práticas de TI Verde adotadas pelas organizações, analisando-se, ainda, os seus benefícios. Espera-se que os resultados aqui obtidos possam estimular acadêmicos e praticantes no estudo e na implementação de diferentes iniciativas de TI Verde que venham a tornar os sistemas mais eficientes e eficazes.

\section{A TI VERDE COMO UM NOVO TÓPICO DE INTERESSE NA ÁREA DE SI}

O contínuo crescimento do uso da TI fez surgir uma preocupação relacionada às questões ambientais, ligadas especialmente ao mau uso e ao descarte dos equipamentos eletrônicos. Somados os gastos necessários para manter a infraestrutura de TI com servidores, computadores, monitores e demais periféricos funcionando adequadamente, a área de TI já representa a terceira maior fonte de consumo de energia dentro das grandes empresas. Segundo o IDC, atualmente se gasta em energia e refrigeração cerca de 50 centavos de dólar para cada dólar investido em equipamentos computacionais, esperando-se que esta tendência cresça 54\% nos próximos quatro anos (IBM, 2007). Considerando-se que o número de servidores em datacenters aumentou em seis vezes na última década e os preços da energia REAd | Porto Alegre - Edição 77 - N 1 - janeiro/abril 2014 - p. 1-30 
TI Verde: uma análise dos principais benefícios e práticas utilizadas pelas organizações

elétrica aumentaram no mundo todo, o custo operacional destes datacenters continuará crescendo firmemente (SARKAR e YOUNG, 2009).

De acordo com um estudo da Consultoria Gartner (2007), os equipamentos de informática são responsáveis por $2 \%$ das emissões de $\mathrm{CO}^{2}$ em todo mundo, o que corresponde à quantidade emitida por todos os aviões existentes. Os datacenters são responsáveis por $23 \%$ da emissão de gases de toda TI, enquanto os PCs e os monitores atingem $40 \%$. Outro problema que começa a preocupar tanto empresas quanto a sociedade é o descarte de equipamentos eletroeletrônicos obsoletos. Em 2010, foram vendidos 13,7 milhões de computadores no Brasil, que passou a ocupar a quarta posição no ranking mundial dos países que mais vendem PCs (IDC, 2011). A preocupação passa a ser para onde irão todos esses equipamentos daqui a dez anos. Boa parte deles utiliza substâncias tóxicas em sua fabricação, como chumbo e mercúrio, que podem contaminar o solo ou os lençóis freáticos. Incinerar todo esse lixo também não é uma boa saída, pois os gases eliminados na incineração são altamente tóxicos e cancerígenos (SILVA, 2009).

Essas estatísticas demonstram como o relacionamento entre o uso da TI e as suas consequencias no meio ambiente deve ser amplamente discutido por diferentes públicos, seja em fóruns, encontros científicos e, até mesmo, dentro da esfera governamental. Nesse contexto, a TI Verde desponta como a mais recente manifestação de práticas de negócio sustentáveis (BROOKS, WANG e SARKER, 2010), sendo usada como um termo genérico para medidas e atividades relacionadas à TI que buscam contribuir com os objetivos orientados ambientalmente de sustentabilidade corporativa e responsabilidade social (CHEN, BOUDREAU e WATSON, 2008).

A TI Verde não é um conceito bem definido, nem um conjunto de práticas uniformemente aceitas. Na linguagem dos executivos, a TI Verde tem sido associada na maioria das vezes às tecnologias e iniciativas para reduzir os custos de energia, refrigeração e estado real com as operações de TI (RASMUSSEN, 2011), o que tem feito com que pesquisadores proponham a necessidade de uma nova subárea de SI, denominada Energy Informatics (WATSON, BOUDREAU e CHEN, 2010). Essa preocupação tem se refletido nos principais fornecedores de tecnologia (como IBM, HP, Dell, Sun Systems, dentre outros) que têm continuamente proposto iniciativas para melhorar o desempenho energético de seus projetos de tecnologia. Embora muita atenção venha sendo dada à TI Verde na literatura comercial, ressalta-se que este foco exclusivo nas tecnologias de informação é bastante 
Guilherme Lerch Lunardi, Renata Simões \&Ricardo Saraiva Frio

restrito e deveria ser estendido aos Sistemas de Informação, definido como um conjunto integrado e cooperativo de pessoas, processos, softwares e hardwares para suportar objetivos individuais, organizacionais e da sociedade. Ela aparece como uma forma de combater ou amenizar os problemas socioambientais por meio do desenvolvimento de novas tecnologias, da conscientização das pessoas e da seleção de fornecedores que tenham projetos sustentáveis, entre outras (VELTE, VELTE e ELSENPETER, 2008; HUANG, 2009).

Nesse sentido, Murugesan (2008) define TI Verde como o estudo e a prática de projetar, produzir, utilizar e descartar computadores, servidores e subsistemas associados tais como monitores, impressoras, periféricos de armazenamento e sistemas de rede e comunicação - eficiente e eficazmente com o mínimo ou sem impacto ao meio-ambiente. A TI Verde também luta para atingir a viabilidade econômica e melhorar o uso e o desempenho dos sistemas, respeitando as responsabilidades sociais e éticas. Portanto, ela inclui as dimensões de sustentabilidade ambiental, eficiência energética e custo total de propriedade, que inclui o custo de descarte e reciclagem. Em outras palavras, é o estudo e a prática de utilizar os recursos computacionais de forma eficiente.

De acordo com Molla et al. (2008), existem quatro elementos que precisam ser considerados na definição de TI Verde: 1) o direcionamento aos desafios em torno da infraestrutura de TI; 2) as contribuições da TI para reduzir os impactos ambientais causados pelas atividades de TI; 3) o suporte da TI às práticas de negócios sustentáveis ambientalmente; e 4) o papel da TI na economia de baixa emissão de gases. Assim, para entender e estudar compreensivamente a TI Verde é necessário considerar o consumo de energia e o seu gerenciamento, as práticas de manufatura, o projeto e as operações de datacenters, a reciclagem e o descarte dos equipamentos computacionais, os assuntos de custos de propriedade, o desempenho dos sistemas e o uso de sistemas eficientes, e as práticas ambientais, sociais e éticas relacionadas à aquisição, uso e descarte da TI (BROOKS, WANG e SARKER, 2010).

\section{MOTIVOS E ATITUDES QUE IMPULSIONAM O USO DE PRÁTICAS VERDES NA ÁREA DE TI}

A adoção da TI Verde diferencia-se da adoção de uma TI qualquer, especialmente pela importância que as questões éticas e de sustentabilidade possuem no processo de tomada de REAd | Porto Alegre - Edição 77 - N 1 - janeiro/abril 2014 - p. 1-30 
TI Verde: uma análise dos principais benefícios e práticas utilizadas pelas organizações

decisão. Enquanto que a adoção de uma TI é usualmente motivada pelos potenciais benefícios econômicos do uso dessa tecnologia, as práticas de TI Verde são motivadas também por serem uma preocupação do planeta, mesmo que os benefícios econômicos possam não ser tangíveis no curto prazo. Organizações que estão preocupadas com as suas responsabilidades sociais e ambientais, com a sustentabilidade dos negócios e a TI Verde, têm tratado essas questões elaborando políticas claras quanto à aquisição de equipamentos (com menor consumo de energia, materiais reciclados, materiais não poluentes, dentre outros), uso de computadores e impressoras (através de processos computacionais mais eficientes, virtualização, diminuição de impressões, remanufatura de cartuchos, uso de papel reciclado...) e até mesmo a disposição dos computadores e datacenters (menores, com menor consumo, melhor refrigeração e etc.).

Buscar a sustentabilidade não significa abandonar o pensamento econômico. Até mesmo porque a economia é direcionada para o problema de alocar recursos escassos, e recursos como as energias livres de emissão de gases e os componentes eletroeletrônicos são particularmente recursos escassos (WATSON, BODREAU e CHEN, 2010). Embora a adoção de práticas verdes aplicadas à área de TI traga uma série de benefícios às organizações, muitas vezes a sua adoção é motivada pela pressão crescente dos concorrentes, consumidores e grupos da comunidade para implantar práticas empresariais sustentáveis (LADEIRA, COSTA e ARAUJO, 2009). Os fornecedores, por exemplo, fornecem serviços ou produtos que consomem energia e outros recursos naturais não renováveis. Graças à concorrência, eles irão competir tentando tornar as suas operações mais eficientes.

Os clientes também exercem uma grande pressão sobre os fornecedores de produtos eletroeletrônicos, porque são eles que pagam o último custo de todo consumo de energia. Além da preocupação quanto aos gastos de energia, alguns consumidores, no seu papel de cidadãos, têm se tornado ativistas pela sustentabilidade, pressionando fornecedores e os governos a reduzirem a emissão de gases. Ainda assim, a concorrência e a pressão dos clientes, por conta própria, nem sempre criam resultados que atendam aos interesses de longo prazo da sociedade, especialmente quando se está tentando criar uma civilização sustentável. Por isso, em algumas situações, o governo precisa intervir e emitir leis e regulações que mudem a base de competição dos fornecedores e canalize o comportamento do consumidor em direções socialmente desejáveis. No Brasil, por exemplo, foi aprovada no final de 2010 a 
Guilherme Lerch Lunardi, Renata Simões \&Ricardo Saraiva Frio

lei estabelecendo critérios para coleta, reciclagem e descarte de eletrodomésticos, eletroeletrônicos e componentes (IDG NOW, 2008; BRAUN, 2010).

Diferentes grupos ambientais também podem influenciar a inovação na área de TI. O Greenpeace, por exemplo, apresenta relatórios periódicos classificando os fornecedores de produtos eletroeletrônicos quanto ao seu impacto no meio ambiente. Além de divulgar seu "ranking verde", a organização não governamental cobra pessoalmente que as empresas sigam suas metas (IDG NEWS SERVICE, 2009). A pressão em cima das empresas não se aplica apenas a reduzir as emissões de $\mathrm{CO}^{2}$, mas também à aplicação de ações como eliminação de componentes químicos prejudiciais ao meio ambiente, taxa de reciclagem, recolhimento de componentes, divulgação de informações e etc.

\section{MÉTODO DE PESQUISA}

A pesquisa se trata de um estudo exploratório-descritivo, compreendendo uma etapa quantitativa, de modo a identificar as práticas de TI Verde adotadas pelas organizações, e outra de caráter mais qualitativo, buscando descrever os benefícios organizacionais dessas práticas. Buscaram-se anúncios publicados eletronicamente em sítios brasileiros, através do site de busca Google, utilizando descritores como "TI Verde", “Green IT", "práticas verdes”, “sustentabilidade e TI”, “TI sustentável”, “adoção”, “caso”, “exemplos”, dentre outros. Cada anúncio encontrado foi lido e analisado, de modo a certificar-se que as práticas identificadas estavam relacionadas ao tema pesquisado. Além das práticas, os artigos que referenciavam empresas que haviam adotado TI Verde foram identificados, sendo o nome das empresas citadas e as principais mudanças ocorridas em virtude da adoção de tais práticas analisadas.

Foram encontrados 202 diferentes anúncios abordando o tema TI Verde, publicados sob a forma de artigos, cases, entrevistas, notícias e sites institucionais, no período de junho de 2006 a setembro de 2011, o que totalizou aproximadamente 260 páginas de análise. Os principais assuntos abordados tratavam do conceito de TI Verde, das aplicações de TI Verde, do que os fornecedores de TI estão fazendo quanto a esta temática, de pesquisas sobre o tema realizadas junto a empresas e seus gestores, de leis e regulamentações ligadas à TI Verde, dos benefícios e vantagens da TI Verde e dos investimentos e custos relacionados à TI Verde todos eles predominantemente obtidos em revistas e sites comerciais. Dentre as fontes com maior representatividade, destacaram-se as seguintes: Computerworld (65 documentos), Itweb 
TI Verde: uma análise dos principais benefícios e práticas utilizadas pelas organizações

(47), Info Online (37) e PCWorld (19) (tabela 1). Os anúncios cujas revistas apareceram uma única vez foram agrupados na fonte outros (totalizando 13 documentos).

Tabela 1 - Fontes consultadas

\begin{tabular}{|c|c|c|}
\hline Fonte & $\mathbf{n}$ & $\%$ \\
\hline Computerworld & 65 & $32,2 \%$ \\
\hline Itweb & 47 & $23,3 \%$ \\
\hline Info Online & 37 & $18,3 \%$ \\
\hline PCWorld & 19 & $9,4 \%$ \\
\hline Information Week & 9 & $4,5 \%$ \\
\hline Sites corporativos & 5 & $2,5 \%$ \\
\hline $\mathrm{CIO}$ & 3 & $1,5 \%$ \\
\hline Codi & 2 & $1,0 \%$ \\
\hline$H S M$ & 2 & $1,0 \%$ \\
\hline Outros & 13 & $6,4 \%$ \\
\hline Total & 202 & 100 \\
\hline
\end{tabular}

Quanto ao ano de publicação dos artigos (tabela 2), percebe-se que o movimento de TI Verde ainda é recente, aparecendo com esta nomenclatura somente a partir de 2006 (com a presença de dois artigos). O elevado número de artigos publicados entre 2008 e 2009 pode ser explicado pela crise econômica mundial ocorrida em meados de 2008, que fez com que o preço do petróleo disparasse, o crédito diminuísse e os gastos com energia aumentassem consideravelmente. Certamente, a crise foi um motivador para a implantação de iniciativas dessa natureza (MONTE, 2009c).

Tabela 2 - Ano de publicação das fontes consultadas

\begin{tabular}{c|c|c}
\hline Ano & n & \% \\
\hline $2011^{*}$ & 14 & 7,0 \\
\hline 2010 & 45 & 22,3 \\
\hline 2009 & 75 & 37,1 \\
\hline 2008 & 53 & 26,2 \\
\hline 2007 & 13 & 6,4 \\
\hline 2006 & 2 & 1,0 \\
\hline Total & $\mathbf{2 0 2}$ & $\mathbf{1 0 0 , 0}$ \\
\hline * Coleta finalizada
\end{tabular}

* Coleta finalizada em setembro de 2011

Fonte: Dados da pesquisa.

Como forma de tratamento dos dados, foi utilizada a técnica da análise temática ou categorial que, de acordo com Bardin (2002), baseia-se em operações de desmembramento do texto em unidades, ou seja, descobrir os diferentes núcleos de sentido que constituem a comunicação e, posteriormente, realizar o seu reagrupamento em classes ou categorias. Assim, procedeu-se à etapa de codificação e categorização, em que, a partir de recortes em unidades de contexto e de registro, formaram-se sete categorias, atendendo os requisitos de 
Guilherme Lerch Lunardi, Renata Simões \&Ricardo Saraiva Frio

exclusão mútua, homogeneidade e pertinência. As diferentes práticas verdes identificadas nos artigos analisados permitiram formar as seguintes categorias:
a) práticas de conscientização;
b) datacenter verde;
c) descarte e reciclagem;
d) fontes alternativas de energia;
e) hardware;
f) impressão; e
g) software.

Após a categorização, selecionaram-se os artigos que possuíam exemplos de empresas que haviam adotado práticas de TI Verde, tornando possível analisar a disseminação de tais práticas entre as organizações. Nas 202 publicações analisadas, pôde-se encontrar 111 diferentes organizações, apresentando a adoção de uma ou mais práticas de TI Verde. Desse total, 44 (39,6\%) eram empresas ligadas à área de tecnologia, divididas em fornecedoras de equipamentos eletroeletrônicos (06), computadores e dispositivos (20), e serviços de informação e internet (18). O restante $(67 ; 60,4 \%)$ era formado por empresas distribuídas em diferentes setores da economia, destacando-se empresas do setor industrial (26), financeiro (16), educação (7) e governamental (6).

Em seguida, cada artigo foi analisado com o intuito de identificar os diferentes benefícios associados a cada prática. A codificação e categorização desses benefícios seguiu a mesma metodologia utilizada na identificação das práticas adotadas pelas organizações, o que originou nove categorias de benefícios:
a) redução de custos;
b) redução do consumo de energia;
c) economia de espaço;
d) imagem institucional;
e) economia de papel;
f) redução de emissão de gases;
g) redução de insumos;
h) redução do lixo eletrônico; e
i) maior ciclo de vida.

REAd | Porto Alegre - Edição 77 - N 1 - janeiro/abril 2014 - p. 1-30 
TI Verde: uma análise dos principais benefícios e práticas utilizadas pelas organizações

\section{RESULTADOS}

A análise de conteúdo dos 202 artigos analisados permitiu categorizar as principais práticas de TI Verde adotadas pelas organizações. No geral, 37 práticas foram identificadas, sendo agrupadas em sete categorias. A identificação das práticas mais disseminadas se deu através da simples contagem (distribuição de frequência) do número de ocorrências de cada prática citada nos anúncios como sendo utilizada pelas empresas identificadas no estudo (tabela 3).

Embora algumas dessas práticas exijam elevados investimentos para a sua implementação, boa parte delas pode ser adotada sem que a saúde financeira da organização seja comprometida, dependendo muitas vezes apenas do esforço das pessoas e do apoio da organização para o seu sucesso. Neste grupo de práticas, encontram-se as práticas de conscientização, como as campanhas internas focadas no impacto ambiental, a escolha de fornecedores verdes, a presença de uma política de sustentabilidade, o teletrabalho, a construção de prédios verdes, a análise da eficiência energética dos equipamentos eletroeletrônicos e a presença de comitês de sustentabilidade. Dados de um estudo da consultoria Gartner apontam que o custo potencial da energia e a emissão de $\mathrm{CO}^{2}$ liberado pelas empresas poderia diminuir em 50\% através de um melhor gerenciamento do uso da energia nos PCs, monitores e impressoras como, por exemplo, encorajando os funcionários a desligá-los (MINGAY, 2007). Campanhas estimulando esse tipo de comportamento aparecem como a prática de conscientização mais comum entre as empresas analisadas $(\mathrm{n}=15)$.

Tabela 3 - Principais práticas de TI Verde adotadas pelas organizações

\begin{tabular}{l|c}
\hline \multicolumn{1}{c|}{$\quad$ Práticas de TI Verde } & n \\
\hline Práticas de conscientização & 15 \\
campanhas de conscientização & 13 \\
fornecedores verdes & 13 \\
política de sustentabilidade & 7 \\
teletrabalho/vídeo conferência & 3 \\
prédio verde & 1 \\
comitês de sustentabilidade & 1 \\
análise de eficiência energética & \\
\hline Datacenter Verde & 39 \\
consolidação de servidores & 15 \\
consolidação de desktops & 15 \\
modernização do datacenter & 3 \\
terceirização de servidores & \\
\hline Descarte e Reciclagem & 16 \\
reciclagem de peças, cartuchos e equipamentos & 13 \\
descarte correto & $1-30$
\end{tabular}

REAd | Porto Alegre - Edição 77 - N 1 - janeiro/abril 2014 - p. 1-30 
Guilherme Lerch Lunardi, Renata Simões \&Ricardo Saraiva Frio

\begin{tabular}{l|c} 
recolhimento de materiais & 8 \\
doação ou entrega de equipamentos & 7 \\
estímulo para os recicladores & 4 \\
leis de regulamentação & 2 \\
trade-in (incentivo à entrega do equipamento antigo na compra de um novo) & 2 \\
\hline Fontes alternativas de energia & \\
uso de energias renováveis & 9 \\
aproveitamento do calor para outros fins & 1 \\
aproveitamento da água & 1 \\
\hline Hardware & \\
equipamentos mais eficientes & 25 \\
substituição de monitores CRT por LCD & 10 \\
eliminação de componentes nocivos nos produtos & 6 \\
produtos novos com componentes reciclados & 3 \\
aumento do ciclo de vida dos produtos & 2 \\
\hline Impressão & \\
terceirização de impressões & 8 \\
monitorar impressões & 7 \\
digitalização de documentos & 6 \\
impressão frente-e-verso & 6 \\
consolidação de impressoras & 4 \\
uso de papel reciclado & 2 \\
uso de multifuncionais & 1 \\
\hline Software & 9 \\
sistemas de gerenciamento de energia & 7 \\
aplicativos eficientes & 1 \\
sistemas de controle (emissão de gases, qualidade da água) & \\
sistema para projetar produtos mais eficientes & \\
\hline
\end{tabular}

Fonte: Dados da pesquisa.

A seleção de fornecedores verdes também aparece como uma prática bastante comum $(n=13)$. Algumas organizações têm feito suas escolhas entre fornecedores de TI, dando preferência aos ambientalmente responsáveis - como aqueles que descartam adequadamente seus equipamentos, investem em programas de reciclagem, possuem programa de retorno de materiais, garantem produtos livres de chumbo, que sejam recicláveis e econômicos no consumo de energia, além de usarem embalagens recicláveis. Algumas empresas chegam a aplicar questionários com questões relacionadas ao meio-ambiente como forma de definir o fornecedor com base na pontuação obtida nesse documento (YURI, 2009).

Outra prática comum neste grupo foi a presença de políticas de sustentabilidade $(\mathrm{n}=$ 13). Tal prática foi apontada em um estudo conduzido pela IBM como uma iniciativa realizada ou planejada por mais de $70 \%$ das companhias médias brasileiras para reduzir o impacto ambiental do uso da tecnologia (COMPUTERWORLD, 2009b). Sustentabilidade, responsabilidade social e TI Verde ganham cada vez mais destaque nas estratégias corporativas e os gestores de TI devem estar conscientes que isso vai muito além da troca de equipamentos, e que ações de responsabilidade social e projetos ligados ao meio ambiente 
TI Verde: uma análise dos principais benefícios e práticas utilizadas pelas organizações

fazem com que a empresa passe a ser percebida com mais valor pelo mercado e pela sociedade.

O uso de videoconferências e teletrabalho $(n=7)$ aparece como uma forte tendência entre as práticas de conscientização, especialmente por aparecerem exemplos de sua aplicação em anúncios publicados ainda mais recentemente (entre 2009 e 2011). Essa prática evita o deslocamento dos profissionais, elimina os custos e os danos do transporte de pessoas, bem como reduz os gastos com telefonia. Um bom exemplo é o do Banco Itaú, que implementou um sistema de videoconferências, a partir do qual são realizadas cerca de 200 reuniões mensais virtuais entre profissionais de várias unidades, resultando em uma economia de 80 toneladas de $\mathrm{CO}^{2}$, que seriam emitidos pelos diversos meios de transporte utilizados por seus profissionais (AMERICANO, 2010).

Com relação à categoria Datacenter Verde, constata-se que a adoção de práticas sustentáveis nesse tipo de ambiente pode contabilizar ganhos significativos, embora exijam elevados investimentos de capital. Os computadores atuais estão cada vez mais exigentes em termos de energia em função do seu alto poder de processamento e para garantir bons resultados é preciso dar atenção a essa questão. As práticas verdes direcionadas aos datacenters dizem respeito, especialmente, à virtualização, seja através da consolidação de desktops $(\mathrm{n}=15)$ ou, ainda, dos servidores $(\mathrm{n}=39)$ - esta última prática aparece como a mais citada entre as empresas analisadas no estudo, sendo adotada por 35\% delas. Enquanto que o pensamento comum da área de TI era o de ter um servidor por serviço, de modo a garantir maior segurança e disponibilidade dos serviços na rede (a uma elevada taxa de ociosidade), a consolidação de servidores consiste em usar apenas uma máquina física com diversas máquinas virtuais, sendo uma para cada servidor. Essa nova abordagem garante o isolamento dos servidores e apresenta as vantagens de aumentar a sua taxa de utilização, reduzindo os custos operacionais, criando ambientes mais flexíveis e reduzindo os custos de administração.

A consolidação de servidores na Ticket Serviços, empresa responsável pelos produtos Ticket Restaurante, Alimentação, Seguros, Gestão de Frotas e Combustível, consumiu R \$ 980 mil em investimentos para agrupar oito servidores de baixa plataforma em uma única máquina. O projeto ajudou a empresa a reduzir custos e riscos operacionais, além de conquistar agilidade em todo o gerenciamento da infraestrutura, economizando por ano cerca de R\$ 500 mil (YURI, 2008). Com relação à consolidação de desktops, tem-se destacado o uso de terminais do tipo thin client, onde os usuários são conectados a um servidor central que 
realiza todo o processamento sem que haja perda para o usuário final, economizando, em contrapartida, quase $80 \%$ de energia do que uma estação normal de trabalho (GUPTA, 2010).

Datacenters mais verdes não só economizam energia, como também reduzem a necessidade de expansão de infraestrutura para lidar com a demanda crescente por energia e mais resfriamento. Por isso, a modernização dos datacenters $(n=15)$ em funcionamento torna-se bastante valiosa para as organizações. Jonathan Koomey, professor da Stanford University, afirma que para cada US\$ 20 dólares gastos a mais em uma fonte eficiente, US\$ 100 dólares são economizados apenas com refrigeração e equipamentos de infraestrutura (COMPUTERWORLD, 2009c).

Já as práticas de Descarte e Reciclagem mostram um maior comprometimento das empresas quanto à utilização, reciclagem e descarte dos recursos naturais não-renováveis. As práticas verdes que vêm sendo adotadas correspondem à reciclagem de peças, cartuchos e equipamentos $(\mathrm{n}=16)$, ao descarte correto de componentes que podem ser reutilizados ou que precisam ser descartados $(n=13)$, ao recolhimento de materiais $(n=8)$, à doação de equipamentos obsoletos $(n=7)$, ao estímulo dado aos recicladores $(n=4)$, às leis de regulamentação $(\mathrm{n}=2)$ e o incentivo à entrega do equipamento antigo na compra de um novo - conhecido como trade-in $(\mathrm{n}=2)$. À medida que mais computadores são adquiridos, cada vez mais o obsoletismo se torna um problema quando o assunto é o seu descarte.

Atualmente, quase todo o material dos PCs é reciclável, com exceção do vidro de monitores, que leva chumbo na fabricação. No Brasil, um bom número de empresas de tecnologia adota o recondicionamento de seus componentes, como peças e cartuchos. A HP, por exemplo, transforma parte dos seus cartuchos em material reutilizável e projeta impressoras e scanners para receber a matéria-prima reciclada - $20 \%$ da matéria-prima vem de resíduos do próprio processo produtivo. A Xerox oferece estímulos financeiros para os seus revendedores recolherem o material. De $60 \%$ a $80 \%$ dos cartuchos retornam, sendo descaracterizados no centro industrial da empresa no Rio de Janeiro, dos quais $89 \%$ dos materiais são vendidos; o restante vai para aterros industriais. Por mês, o centro de reciclagem da Xerox processa 115 mil toneladas de lixo tecnológico. Já a Epson disponibiliza mais de 150 pontos autorizados para seus clientes entregarem cartuchos sem utilização, os quais alimentarão fornos na indústria cimenteira (FERREIRA, 2009).

Uma alternativa à reciclagem são as doações. A seguradora de saúde Highmark, por exemplo, doa seus computadores a organizações sem fins lucrativos e a igrejas (HOOVER, 
TI Verde: uma análise dos principais benefícios e práticas utilizadas pelas organizações

2009). Já a Klabin renova a cada ano $25 \%$ do seu parque tecnológico, doando suas máquinas usadas principalmente às comunidades dos municípios onde estão instaladas as 17 fábricas da empresa no país (SPOSITO, 2008).

Outra constatação, relacionada ao elevado consumo de energia por parte dos equipamentos de informática, é a presença de algumas iniciativas visando obter energia através de Fontes Alternativas. A geração de energia alternativa passa pelo uso de biodiesel, combustíveis não fósseis, vento e até mesmo as ondas do mar - todas energias renováveis (n =9). A Dell, por exemplo, economizou cerca de $35 \%$ de energia em suas unidades nos Estados Unidos e $20 \%$ nas instalações globais por usar fontes renováveis de energia (IDG NEWS SERVICE, 2009). Entre 2005 e 2007, a Dell dobrou as compras de energia proveniente de combustíveis não fósseis. Entretanto, fontes de energia alternativa não são baratas, e para muitas empresas não será prático colocar os datacenters em locais onde a energia eólica ou hidroelétrica sejam acessíveis, além de o retorno da energia solar ser demorado (HOOVER, 2009).

Com relação ao desenvolvimento de novos equipamentos de informática - Hardware, PCs, impressoras e outros periféricos representam uma fácil e significativa oportunidade para melhorias, através da aplicação de boas práticas de sustentabilidade. O desenvolvimento de equipamentos mais eficientes e econômicos energeticamente, a substituição de monitores CRT por LCD, a eliminação de componentes nocivos nos produtos, o uso de componentes reciclados na confecção de produtos novos e o aumento do ciclo de vida dos produtos são algumas dessas práticas. Em relação à fabricação de componentes mais eficientes $(n=25)$, muitos fornecedores de TI têm investido na redução do gasto de energia em sua linha de computadores e componentes - nesta pesquisa, 16 fornecedores de TI destacaram a adoção dessa prática (equivalentes a $36 \%$ dos 44 fornecedores identificados). Alguns modelos de desktop melhoraram seu consumo de energia em $50 \%$ em menos de três anos, enquanto na linha de computadores pessoais, a Dell anunciou recentemente o Studyo Hybrid, um desktop com componentes de notebook que consegue uma economia energética de $70 \%$ em relação a um computador de mesa comum (FERRARI, 2009b). Esta prática não se aplica apenas aos fornecedores de TI, o Banco Matone, por exemplo, possui uma forte orientação para economia de energia e sustentabilidade. Além da troca dos monitores de todos os computadores para padrão LCD (com menor consumo do que os monitores CRT até então utilizados), a empresa calculou uma economia de pelo menos $48 \%$ em energia pela instalação 
de novos servidores mais econômicos e de melhor desempenho, somados à substituição dos equipamentos antigos (DOMINGUES, 2011).

Outra prática bastante comum é a substituição de monitores $(\mathrm{n}=10)$. A Tambasa, empresa atacadista mineira, além de adquirir novas máquinas, trocou seus monitores. Todos os tubos CRT foram substituídos pelas telas LCD, que ocupam menos espaço e consomem menos energia. O investimento total foi de aproximadamente $\mathrm{R} \$ 95$ mil, tendo o retorno sobre o investimento previsto para um ano (BALIEIRO, 2008).

Já a eliminação de componentes nocivos $(n=6)$ tem preocupado tanto fornecedores de TI quanto usuários. Já existem vários modelos à venda que alegam não utilizar metais pesados em sua fabricação, o que os torna mais ecologicamente corretos. A USP, por exemplo, criou um "selo verde", atribuído a todos os computadores desenvolvidos com especificações que garantem menor consumo de energia e seu processo de produção exclui o uso de substâncias tóxicas, como o chumbo (MONTE, 2009a).

Com relação à aplicação de práticas de TI Verde ligadas à Impressão, uma série de oportunidades pode ser explorada. A maior preocupação ainda é o uso do papel, mas com a realização de algumas medidas, as organizações podem reduzir o impacto ambiental das impressoras e das impressões. As práticas utilizadas têm sido a terceirização das impressões $(\mathrm{n}=8)$, o monitoramento das impressões $(\mathrm{n}=7)$, a digitalização de documentos $(\mathrm{n}=6)$, a impressão frente-e-verso $(n=6)$, a consolidação de impressoras $(n=4)$, o uso de papel reciclado $(n=2)$ e o uso de multifuncionais $(n=1)$.

Várias empresas têm optado ultimamente pela terceirização da impressão, o que reduz os altos custos de manutenção e evita a baixa qualidade de impressão, além de gerar um maior controle sobre as impressões realizadas. Com isso, a empresa controla quem imprimiu, o que foi impresso e quanto custou (INFO CORPORATE, 2008b). A Boehringer, indústria farmacêutica, reduziu em 50\% o volume de papel utilizado, simplesmente monitorando as impressões através de uma solução que exige dos colaboradores a utilização do crachá para autorizar a impressão (DREHER, 2010). Já a digitalização de documentos é outra prática crescente. A AGF Seguros, por exemplo, acaba de lançar um modelo de contrato com certificação digital, cuja apólice eletrônica substitui os kits que são enviados anualmente para segurados e corretores para cada contrato fechado. A empresa estima que a certificação digital preserve uma árvore a cada 600 kits emitidos, além de trazer benefícios de segurança para todo o processo - o envio da apólice para o corretor, em formato PDF com assinatura digital, 
TI Verde: uma análise dos principais benefícios e práticas utilizadas pelas organizações

evita problemas com falsificações e extravios, além de o documento eletrônico ficar armazenado no datacenter da AGF e poder ser acessado a qualquer hora (INFO CORPORATE, 2008a).

E, por fim, aparecem as práticas associadas ao melhor funcionamento dos Softwares. Elas podem ser vistas sob a ótica de tornarem os programas computacionais mais eficientes $\mathrm{n}=7$ - consumindo menos energia, otimizando seu processamento e desabilitando funções ou dispositivos quando não utilizados ou, ainda, para gerenciar o consumo de energia de acordo com a utilização do equipamento $(n=9)$, controlar a emissão de gases ou a qualidade da água $(n=7)$ e projetar novos produtos mais eficientes $(n=1)$.

Um exemplo de aplicativos mais eficientes é o da empresa de consultoria Booz \& Company, que através de configurações de energia, obteve contribuições entre $5 \%$ e 10\% com a desativação de sistemas (DREHER, 2010). Outra novidade é a tecnologia de gerenciamento de energia do sistema operacional Windows 7, que fornece recursos eficientes de plataforma e processador que reduzem o consumo de energia e ajudam a reduzir os custos associados bem superiores aos seus sistemas antecessores (MICROSOFT, 2010). A Cetesb/SP (Companhia de Tecnologia de Saneamento Ambiental) criou um catálogo para unificar os sistemas legados da empresa para controlar a qualidade da água e a poluição de todos os municípios do Estado de São Paulo, integrando quatro grandes sistemas. O uso desse aplicativo auxilia no combate ao impacto ambiental.

Já com relação aos benefícios das práticas verdes aplicadas à área de TI, foram analisados os mesmos 202 artigos, a fim de perceber os ganhos obtidos pelas empresas ao adotarem práticas de TI Verde. Foram incluídas nessa análise apenas as práticas que apresentaram de forma explícita nos artigos analisados algum benefício associado a elas, chegando-se a um total de 30 das 37 práticas originais (tabela 4).

REAd | Porto Alegre - Edição 77 - N 1 - janeiro/abril 2014 - p. 1-30 
Tabela 4 - Benefícios obtidos através da adoção de diferentes práticas verdes adotadas na área de TI

\begin{tabular}{|c|c|c|c|c|c|c|c|c|c|c|}
\hline \multirow[t]{2}{*}{ Práticas } & \multicolumn{10}{|c|}{ Benefícios } \\
\hline & $\begin{array}{l}\text { Redução de } \\
\text { custos }\end{array}$ & $\begin{array}{c}\text { Redução } \\
\text { de Insumos }\end{array}$ & $\begin{array}{l}\text { Redução do } \\
\text { consumo de } \\
\text { energia }\end{array}$ & Imagem & $\begin{array}{l}\text { Redução de } \\
\text { emissão de } \\
\text { gases }\end{array}$ & \begin{tabular}{c|} 
Redução \\
do lixo \\
eletrônico
\end{tabular} & $\begin{array}{l}\text { Maior } \\
\text { ciclo de } \\
\text { vida }\end{array}$ & $\begin{array}{l}\text { Economia } \\
\text { de espaço }\end{array}$ & $\begin{array}{c}\text { Economia } \\
\text { de papel }\end{array}$ & Total \\
\hline $\begin{array}{l}\text { Práticas de conscientização } \\
\text { campanhas de conscientização } \\
\text { fornecedores verdes } \\
\text { política de sustentabilidade } \\
\text { teletrabalho/vídeo conferência } \\
\text { prédio verde }\end{array}$ & $\begin{array}{l}1 \\
1 \\
1 \\
1\end{array}$ & $\begin{array}{l}1 \\
1 \\
1 \\
1 \\
1\end{array}$ & $\begin{array}{l}1 \\
1 \\
1 \\
1 \\
1\end{array}$ & $\begin{array}{l}1 \\
1 \\
1 \\
1 \\
1\end{array}$ & $\begin{array}{l}1 \\
1 \\
1 \\
1 \\
1\end{array}$ & $\begin{array}{l}1 \\
1 \\
1\end{array}$ & $\begin{array}{l}1 \\
1\end{array}$ & & 1 & $\begin{array}{l}8 \\
7 \\
6 \\
5 \\
4\end{array}$ \\
\hline $\begin{array}{l}\text { Datacenter Verde } \\
\text { consolidação de desktops } \\
\text { consolidação de servidores } \\
\text { modernização do datacenter }\end{array}$ & $\begin{array}{l}1 \\
1 \\
1\end{array}$ & 1 & $\begin{array}{l}1 \\
1 \\
1\end{array}$ & $\begin{array}{l}1 \\
1\end{array}$ & $\begin{array}{l}1 \\
1 \\
1\end{array}$ & 1 & 1 & $\begin{array}{l}1 \\
1 \\
1\end{array}$ & & $\begin{array}{l}7 \\
6 \\
4\end{array}$ \\
\hline $\begin{array}{l}\text { Descarte e reciclagem } \\
\text { reciclagem de peças, cartuchos e } \\
\text { equipamentos } \\
\text { doação ou entrega de } \\
\text { equipamentos } \\
\text { leis de regulamentação } \\
\text { descarte correto } \\
\text { recolhimento de materiais } \\
\text { trade-in }\end{array}$ & 1 & $\begin{array}{l}1 \\
1 \\
1 \\
1 \\
1 \\
1\end{array}$ & & $\begin{array}{l}1 \\
1 \\
1 \\
1 \\
1 \\
1\end{array}$ & 1 & $\begin{array}{l}1 \\
1 \\
1 \\
1 \\
1 \\
1\end{array}$ & $\begin{array}{l}1 \\
1 \\
1 \\
1 \\
1\end{array}$ & 1 & & $\begin{array}{l}5 \\
5 \\
4 \\
3 \\
3 \\
3 \\
\end{array}$ \\
\hline $\begin{array}{l}\text { Fontes alternativas de energia } \\
\text { uso de energias renováveis } \\
\text { aproveitamento do calor para } \\
\text { outros fins } \\
\text { aproveitamento da água }\end{array}$ & $\begin{array}{l}1 \\
1 \\
1\end{array}$ & 1 & $\begin{array}{l}1 \\
1 \\
1\end{array}$ & 1 & $\begin{array}{l}1 \\
1\end{array}$ & & & 1 & & $\begin{array}{l}5 \\
3 \\
3\end{array}$ \\
\hline $\begin{array}{l}\text { Hardware } \\
\text { equipamentos mais eficientes } \\
\text { substituição de monitores CRT } \\
\text { por LCD } \\
\text { produtos com componentes } \\
\text { reciclados } \\
\text { eliminação de componentes } \\
\text { nocivos }\end{array}$ & $\begin{array}{l}1 \\
1\end{array}$ & $\begin{array}{l}1 \\
1\end{array}$ & $\begin{array}{l}1 \\
1\end{array}$ & 1 & $\begin{array}{l}1 \\
1\end{array}$ & $\begin{array}{l}1 \\
1\end{array}$ & $\begin{array}{l}1 \\
1\end{array}$ & $\begin{array}{l}1 \\
1\end{array}$ & 1 & $\begin{array}{l}5 \\
4 \\
4 \\
3\end{array}$ \\
\hline
\end{tabular}

REAd | Porto Alegre - Edição 77 - $\mathrm{N}^{\circ} 1$ - janeiro/abril 2014 - p. 1-30 
TI Verde: uma análise dos principais benefícios e práticas utilizadas pelas organizações

\begin{tabular}{|c|c|c|c|c|c|c|c|c|c|c|}
\hline $\begin{array}{l}\text { aumento do ciclo de vida dos } \\
\text { produtos }\end{array}$ & 1 & & & & & 1 & 1 & & & 3 \\
\hline $\begin{array}{l}\text { Impressão } \\
\text { monitorar impressões } \\
\text { impressão frente-e-verso } \\
\text { digitalização de documentos } \\
\text { terceirização de impressões }\end{array}$ & $\begin{array}{l}1 \\
1 \\
1 \\
1 \\
\end{array}$ & $\begin{array}{l}1 \\
1 \\
1\end{array}$ & $\begin{array}{l}1 \\
1 \\
\end{array}$ & 1 & 1 & & 1 & $\begin{array}{l}1 \\
1 \\
1 \\
1 \\
\end{array}$ & $\begin{array}{l}1 \\
1 \\
1 \\
1 \\
\end{array}$ & $\begin{array}{l}5 \\
5 \\
6 \\
4 \\
\end{array}$ \\
\hline $\begin{array}{l}\text { Software } \\
\text { sistemas de gerenciamento de } \\
\text { energia } \\
\text { aplicativos eficientes } \\
\text { sistemas de controle (emissão de } \\
\text { gases) } \\
\text { sistema para projetar produtos } \\
\text { eficientes }\end{array}$ & $\begin{array}{l}1 \\
1 \\
1 \\
1\end{array}$ & $\begin{array}{l}1 \\
1\end{array}$ & $\begin{array}{l}1 \\
1 \\
1\end{array}$ & $\begin{array}{l}1 \\
1\end{array}$ & $\begin{array}{l}1 \\
1 \\
1\end{array}$ & & & & & $\begin{array}{l}4 \\
4 \\
4 \\
2\end{array}$ \\
\hline $\begin{array}{l}\text { Total } \\
\end{array}$ & 21 & 20 & 17 & 17 & 17 & 13 & 11 & 11 & 7 & \\
\hline
\end{tabular}

REAd | Porto Alegre - Edição 77 - Nº 1 - janeiro/abril 2014 - p. 1-30 
A análise permitiu classificar os benefícios relatados pelas empresas em nove categorias distintas. Dentre os benefícios que tiveram o maior número de práticas associadas estão a redução de custos (21), a redução de insumos (20), a redução do consumo de energia (17), os benefícios de imagem institucional (17) e a redução de emissão de gases (17). Percebe-se que a adoção dessas práticas traz uma série de ganhos econômicos, ambientais e institucionais, sugerindo que o retorno obtido supera o aumento dos custos de produção provenientes de investimentos de capital e de operação associados à adoção dessas práticas. Os exemplos analisados apontam que essas atividades trazem resultados financeiros positivos e novas oportunidades em segmentos de mercado conscientes ambientalmente.

Benefícios como: redução do lixo eletrônico (13), maior ciclo de vida (11), economia de espaço (11) e economia de papel (7) também tiveram uma série de práticas a elas associadas, porém em menor escala que as citadas anteriormente. Ainda assim, os exemplos analisados destacam essas práticas como de grande potencial para reduzir os impactos ambientais que, de certa forma, também trazem benefícios diretos à organização.

Quanto às práticas de conscientização, pode-se verificar que a sua adoção traz como principais benefícios a redução de custos, a redução de insumos, a redução do consumo de energia, ganhos de imagem institucional e a redução da emissão de gases. Muitas dessas práticas são de fácil adoção, além de exigirem pequenos investimentos, quando comparados aos ganhos que podem trazer à organização. O Itaú Unibanco, por exemplo, se concentrou em analisar práticas que tornem o ambiente de trabalho da instituição mais sustentável, incluindo projetos para reduzir impressões, evitar o deslocamento dos profissionais, aumentar o tempo de vida útil dos equipamentos, entre outros. As ações verdes do departamento de TI também contribuem para construir uma imagem positiva do banco no mercado, recebendo inclusive premiações internacionais (COMPUTERWORLD, 2010). A adoção dessas práticas pode trazer tanto benefícios econômicos, quanto ambientais e institucionais.

Com relação ao datacenter verde, aparecem como principais benefícios a redução de custos, a redução do consumo de energia, a redução de emissão de gases e a economia de espaço. A Revlon, fabricante de cosméticos, optou pela virtualização dos seus servidores, o que permitiu uma redução média de $72 \%$ no consumo de energia (GRUMAN, 2009). Outra empresa que obteve ganhos com a consolidação de servidores foi a Sun Microsystems, obtendo uma economia de 11 mil toneladas de $\mathrm{CO}^{2}$ por ano - o que representa uma redução de $6 \%$ nas emissões da empresa nos Estados Unidos - além de economizar mais de 1 milhão 
TI Verde: uma análise dos principais benefícios e práticas utilizadas pelas organizações

de dólares em custos de eletricidade. Outro benefício exposto pela empresa foi uma redução de 66\% no seu espaço físico (FERRARI, 2009a). A adoção dessas práticas visa prioritariamente benefícios econômicos, mas que acabam indiretamente beneficiando o meioambiente.

Quanto ao grupo de práticas de descarte e reciclagem destacam-se principalmente os benefícios associados à redução de insumos, à imagem institucional e à redução do lixo eletrônico. A Itautec, por exemplo, reciclou 460 toneladas de material eletroeletrônico internamente em 2008. Além disso, o seu programa de sustentabilidade incluiu a recompra de equipamentos para reciclagem, a eliminação do chumbo na fabricação de equipamentos e melhorias na cadeia de suprimentos. As ações ambientais incluíram também otimização de estoque para economizar com embalagens (AFONSO, 2009). Além do aproveitamento dos componentes reciclados, as práticas de descarte reduzem a contaminação pela decomposição de metais (principalmente chumbo e cobre) que usualmente são destinados em aterros sanitários. A adoção dessas práticas oportuniza predominantemente os benefícios ambientais.

Com relação às fontes de energia renováveis, aparecem a redução de custos, a redução do consumo de energia e a redução de emissão de gases como os principais benefícios. A Google, por exemplo, patenteou nos Estados Unidos a ideia de possuir datacenters em alto mar. A ideia é utilizar as ondas e o vento para gerar energia. $\mathrm{O}$ datacenter obtém também uma economia com refrigeração, já que utiliza a água do mar para circular entre os servidores. Outro benefício resultante da adoção dessa prática é quanto à economia com o aluguel de espaços físicos (ZMOGINSKI, 2009). O Banco do Brasil, por sua vez, prioriza os geradores de seus datacenters que possuam menos poluentes, que possam ter limitação de fuligem, além dos que podem utilizar biodiesel, fazendo a sua refrigeração através da captação da água da chuva e com gases não agressivos (CARVALHO, 2008). Tais práticas tornam a organização mais eficaz, pois além do benefício ambiental, a sua adoção oportuniza um interessante ganho financeiro e de imagem entre diferentes públicos.

Quanto aos benefícios associados às práticas de hardware, a redução de custos, a redução do lixo eletrônico e o maior ciclo de vida destacaram-se mais. A Alog Datacenters do Brasil, por exemplo, obteve uma redução na sua conta de energia elétrica de $65 \%$ somente com a substituição dos servidores antigos por equipamentos mais modernos. A empresa obteve além de uma fatura de eletricidade menor, redução de $20 \%$ no espaço ocupado pelas máquinas em um de seus datacenters no Rio de Janeiro (MONTE, 2009b). Já a AMBEV 
reduziu os gastos com energia e evitou o descarte de 15 mil máquinas nos últimos oito anos, através da adoção de thin clients em toda empresa. Além de economizar $90 \%$ da energia consumida por um computador normal, os novos equipamentos possuem maior tempo de vida útil e otimizam o espaço físico na companhia (AMBEV, 2011). A adoção dessas práticas proporciona em sua maioria benefícios econômicos.

Entre as práticas associadas à impressão destacam-se os seguintes benefícios: redução de custos, economia de espaço e economia de papel. Esses ganhos são proporcionados especialmente pela digitalização dos documentos, pelo monitoramento de impressões e pelas impressões frente-e-verso. A digitalização, por exemplo, pode resultar em uma economia de até 30\% nos custos de impressão (HSM Online, 2009). A GM economizou 11 mil árvores, em cinco anos. A redução das suas impressões (em torno de 50\%) passou de seis milhões de páginas por mês para 2,7 milhões, devido a um melhor monitoramento de impressões que passou a cobrar das unidades por folha impressa (CARVALHO, 2008). A adoção dessas práticas pode trazer tanto benefícios econômicos quanto ambientais.

Com relação às práticas de software, pode-se destacar como principais benefícios a redução de custos, a redução do consumo de energia e a redução de emissão de gases. Os softwares têm avançado significativamente em relação à otimização do processamento de dados, de forma a realizar menos operações para efetuar cada tarefa, ou simplesmente realizando todas de uma única vez para manter o processador em modo de economia de energia por mais tempo (HSM Online, 2009). Além disso, os softwares de gerenciamento de impressões, de rede, de consumo de energia, de emissão de gases, de utilização da infraestrutura, assim como os softwares de virtualização, podem auxiliar a organização no combate ao impacto ambiental. A adoção dessas práticas traz benefícios econômicos, ambientais e de melhoria no desenvolvimento de produtos ecologicamente corretos.

\section{CONSIDERAÇÕES FINAIS}

O presente estudo procurou identificar as principais práticas de TI Verde adotadas pelas organizações, bem como seus principais benefícios. A análise, realizada a partir de 202 anúncios publicados na internet, permitiu identificar 37 diferentes práticas de sustentabilidade aplicadas à área de TI que, por meio da análise temática, foram agrupadas em sete categorias: 
TI Verde: uma análise dos principais benefícios e práticas utilizadas pelas organizações

1) práticas de conscientização; 2) datacenter verde; 3) descarte e reciclagem; 4) fontes alternativas de energia; 5) hardware; 6) impressão; e 7) software.

Pôde-se perceber pela leitura dos anúncios encontrados e pela análise realizada, que muitas estratégias politicamente corretas em relação ao meio ambiente vêm ganhando espaço na lista de prioridades dos executivos. A análise realizada permitiu identificar nove categorias distintas de benefícios: 1) redução de custos; 2) redução de insumos; 3) redução de consumo de energia; 4) imagem institucional; 5) redução de emissão de gases; 6) redução do lixo eletrônico; 7) maior ciclo de vida; 8) economia de espaço; e 9) economia de papel.

Aparentemente, o principal motivador para essa mudança de comportamento é o fator econômico, demonstrado pelo grande número de práticas que oportunizam aumento de faturamento ou redução de custos - sejam eles de energia, insumos, papel, água, transporte, manutenção ou descarte. Ainda assim, os benefícios ligados à imagem institucional, à economia de espaço físico, ao respeito ao meio ambiente, e até mesmo à geração de renda, dentre outros, fazem da adoção dessas práticas uma importante ferramenta para implementar ações ambientalmente corretas. Ficou claro, a partir do estudo, que embora algumas práticas exijam elevados investimentos - especialmente aquelas ligadas aos datacenters, às fontes alternativas de energia e à substituição de equipamentos obsoletos por novos - boa parte das práticas de sustentabilidade pode ser adotada sem que a saúde financeira da organização seja comprometida, apenas dependendo do esforço e vontade dos usuários, e do apoio e direcionamento da organização. As práticas ligadas aos datacenters e à substituição de equipamentos obsoletos, identificadas na análise como demandantes de altos investimentos, por outro lado, aparecem como as práticas cujo retorno financeiro é o mais rápido e, por consequente, as mais impactantes na redução de custos da organização. Isso explica o grande número de ocorrências de consolidação de servidores e de desktops, bem como da aquisição de equipamentos mais eficientes.

Ainda sobre as ações mais utilizadas, deve-se destacar o grande número de práticas de conscientização que podem ser adotadas e que, conforme identificado nos anúncios analisados, têm oportunizado diferentes benefícios às organizações, como é o caso da elaboração de campanhas internas de conscientização focadas no impacto ambiental, a preferência por fornecedores verdes e a elaboração de políticas de sustentabilidade. Algumas dessas ações estão diretamente vinculadas ao uso de aplicativos eficientes e à adoção de sistemas de gerenciamento de energia. Quanto às práticas de descarte e reciclagem, deve-se 
destacar que embora existam diferentes possibilidades de implementação, o seu resultado e a sua disseminação entre as empresas ainda não é expressiva, especialmente porque é um tipo de ação onde o ganho financeiro é pouco percebido. Daí a importância de diferentes grupos da sociedade atuarem incentivando ou até mesmo obrigando que as empresas reciclem ou descartem corretamente seus produtos e resíduos sem destino ou uso. Os benefícios associados a essas práticas estão ligados principalmente à redução de insumos, à redução do lixo eletrônico e à imagem institucional.

A pesquisa apresenta como principal limitação a quantificação de práticas de TI Verde apenas de empresas que tiveram suas ações divulgadas; as organizações que utilizam uma ou mais dessas práticas, sem que as mesmas tenham sido divulgadas ou encontradas nas fontes pesquisadas, não foram consideradas no estudo, o que pode distorcer os resultados obtidos. Ainda assim, o fato de estas práticas terem sido identificadas com maior frequência nas fontes pesquisadas sugere que são as mais difundidas entre o universo de empresas referenciadas no estudo.

Com o intuito de contribuir para um maior aprofundamento e entendimento do tema abordado, sugerem-se algumas pesquisas futuras. A primeira é a realização de um ou mais estudos de caso em empresas que adotaram ou estão adotando práticas de sustentabilidade na área de TI, buscando identificar seus principais benefícios, dificuldades de implantação e fatores necessários para o seu sucesso. Segundo, sugere-se a realização de surveys em diferentes setores industriais, de modo a identificar as práticas de TI Verde mais utilizadas e o impacto por elas proporcionado. E, por fim, propõe-se a realização de estudos comparativos entre diferentes países para verificar se a TI Verde é um tema que vem sendo tratado independentemente da cultura ou de ações governamentais, como isenções e benefícios fiscais, que ocorrem de forma distinta.

\section{REFERÊNCIAS}

AMBEV. Projeto da Ambev de tecnologia da informação tem viés de sustentabilidade. 2011. Disponível em: http://www.ambev.com.br/pt-br/valores-ambientais/iniciativas/ti-verde. Acessado em: 20/01/2011.

AMERICANO, A. Data Center ecológico traz economias à Accor. Itweb. 2010. Disponível em: http://www.itweb.com.br/noticias/index.asp?cod=57676. Acessado em: 20/01/2011. 
TI Verde: uma análise dos principais benefícios e práticas utilizadas pelas organizações

AFONSO, R. Itautec recicla 460 toneladas de lixo eletrônico em 2008. Computerworld. 2009. Disponível em: http://computerworld.uol.com.br/gestao/2009/06/17/itautec-recicla-460toneladas-de-lixo-eletronico-em-2008. Acessado em: 20/01/2011.

BALIEIRO, S. Um PC para 20 usuários na Tambasa. Info Corporate. 2008. Disponível em: http://info.abril.com.br/corporate/ti-verde/um-pc-para-20-usuarios-na-tambasa.shtml. Acessado em: 04/11/2008.

BARDIN, L. Análise de conteúdo. Lisboa: Edições 70, 2002.

BRAUN, D. Lei de reciclagem muda de hábitos de empresas e consumidores. PC World. 2010. Disponível em: http://pcworld.uol.com.br/noticias/2010/05/14/lei-de-reciclagem-mudade-habitos-de-empresas-e-consumidores/\#rec:mcl. Acessado em: 14/05/2010.

BROOKS, S.; WANG, X.; SARKER, S. Unpacking Green IT: A Review of the Existing Literature. AMCIS 2010 Proceedings, 2010.

CHEN, A.; BOUDREAU, M.; WATSON, R. Information systems and ecological sustainability. Journal of Systems and Information Technology, Sustainability and Information Systems, v. 10, n. 3, 2008, p. 186-201.

CARVALHO, S. Choque de realidade na TI verde. Info Corporate. 2008. Disponível em: http://info.abril.com.br/corporate/ti-verde/choque-de-realidade-na-ti-verde.shtml. Acessado em: 12/01/2012.

COMPUTERWORLD. TI verde entra no currículo de faculdade em São Paulo. 2009a. Disponível em http://computerworld.uol.com.br/carreira/2009/06/15/ti-verde-entra-nocurriculo-de-faculdade-em-sao-paulo. Acessado em: 15/12/2009.

COMPUTERWORLD. TI verde está nos planos de 70\% das médias empresas brasileiras, diz estudo. 2009b. Disponível em: http://computerworld.uol.com.br/gestao/2009/05/05/tiverde-esta-nos-planos-de-70-das-medias-empresas-brasileiras-diz-estudo. Acessado em: 05/05/2009.

COMPUTERWORLD. TI verde: negócios em linha com o planeta. Guia Executivo para Decisões Estratégicas. 2009c. Disponível em:

http://computerworld.uol.com.br/tecnologia/2009/03/25/ti-verde-negocios-em-linha-com-oplaneta/. Acessado em: 15/12/2010. 
Guilherme Lerch Lunardi, Renata Simões \&Ricardo Saraiva Frio

D'SOUZA, C.; et al. Green products and corporate strategy: an empirical investigation. Society and Business Review, v. 1, n. 2, 2006, p. 144-157.

DOMINGUES, A. Banco Matone ganha produtividade com solução da Dell. Itweb. 2011. Disponível em: http://www.itweb.com.br/voce_informa/interna.asp?cod=18800. Acessado em: 15/03/2011.

DREHER, F. A tecnologia pode contribuir com a sustentabilidade? Itweb. 2010. Disponível em: http://www.itweb.com.br/noticias/index.asp?cod=67459. Acessado em: 23/04/2010.

ELLIOT, S.; BINNEY, D. Environmentally sustainable ICT: Developing corporate capabilities and an industry relevant IS research agenda. PACIS 2008 Proceedings, 2008.

FERRARI, B. O data center verde da Sun. Info Online. 2009a. Disponível: http://info.abril.com.br/ti-verde/. Acessado em: 12/01/2012.

FERRARI, B. O lado verde da Dell. Info Corporate. 2009b. Disponível em http://info.abril.com.br/corporate/ti-verde/o-lado-verde-da-dell.shtml. Acessado em: 12/01/2010.

FERREIRA, L. Para onde vão os cartuchos? Info Corporate. 2009. Disponível em: http://info.abril.com.br/corporate/ti-verde/para-onde-vao-os-cartuchos.shtml. Acessado em: 12/01/2010.

GARTNER. Gartner: Data Centres Account for 23\% of Global ICT C02 Emissions. 2007. Disponível em: http://www.gartner.com/it. Acessado em: 15/03/2011.

GRUMAN, G. Revlon investe em projeto com 400 máquinas virtuais. Infoworld. 2009. Disponível em: http://computerworld.uol.com.br/gestao/2009/06/03/revlon-investe-emprojeto-com-400-maquinas-virtuais. Acessado em: 25/01/2012.

GUPTA, S. Computing with Green responsability. Proceedings of the International Conference and Workshop on Emerging Trends in Technology, 2010.

HOOVER, J. 10 idéias para impulsionar os projetos de TI verde. Itweb. 2009. http://www.itweb.com.br/noticias/noticias_imprimir.asp?cod=54086. Acessado em: 18/01/2011. 
TI Verde: uma análise dos principais benefícios e práticas utilizadas pelas organizações

HSM Online. TI Verde é desafio para as empresas em 2010. 2009. Disponível em: http://br.hsmglobal.com/notas/55585-ti-verde-e-desafio-as-empresas-em-2010. Acesso em: $12 / 11 / 2011$.

HUANG, A. A model for environmentally sustainable information systems development. Journal of Computer Information Systems, v. 49, n. 4, 2009, p. 114-121.

IBM. IBM liderará a nova era de informática eficiente no uso da energia. 2007. Disponível em:http://www.ibm.com/br/systems/optimizeit/cost_efficiency/energy_efficiency/services.pht ml. Acessado em: 15/02/2011.

IDC. Brasil comercializa 13,7 milhões de computadores em 2010 e passa a ocupar a quarta posição no ranking mundial dos países que mais vendem PCs, revela estudo da IDC. Fev 2011. Disponível em: http://www.idclatin.com/news.asp?ctr=bra\&id_release=1918. Acessado em: 20/01/2012.

IDG NEWS SERVICE. Dell, HP e Lenovo perdem posições em ranking 'verde' do Greenpeace. Computerworld. 2009. Disponível em:

http://computerworld.uol.com.br/gestao/2009/03/31/dell-hp-e-lenovo-perdem-posicoes-emranking-verde-do-greenpeace. Acessado em: 31/03/2009.

IDG NOW. Câmara analisa Projeto com regras para descarte de lixo eletrônico. PC World. 2008. Disponível em: http://pcworld.uol.com.br/noticias/2008/01/29/camara-analisa-projetocom-regras-para-descarte-de-lixo-eletronico/\#rec:mcl. Acessado em: 29/01/2008.

INFO CORPORATE. Apólice Digital. 2008a. Disponível em:

http://info.abril.com.br/corporate/ti-verde/apolice-digital.shtml . Acessado em: 15/02/2011.

INFO CORPORATE. Economia frente-verso. 2008b. Disponível em:

http://info.abril.com.br/corporate/ti-verde/economia-frenteverso.shtml . Acessado em: $15 / 02 / 2011$.

ITWEB. Projetos de TI verde estão entre prioridades, diz Gartner. Itweb. 2009. Disponível em: http://www.itweb.com.br/noticias/index.asp?cod=56910. Acessado em: 01/05/2009.

KIM, Y.; KO, M. Identifying Green IT Leaders with Financial and Environmental Performance Indicators. AMCIS 2010 Proceedings, 2010.

REAd | Porto Alegre - Edição 77 - N 1 - janeiro/abril 2014 - p. 1-30 
LADEIRA, W.; COSTA, J.; ARAUJO, C. Green IT e o Processo de Produção de Informação: Uma Análise das Atividades que Produzem Sustentabilidade Ambiental. Anais do XXXIII ENANPAD, 2009.

LANKOSKI, L. Corporate responsibility activities and economic performance: a theory of why and how they are connected. Business Strategy and the Environment, v. 17, n. 8, 2008, p. 536-547.

MICROSOFT. Prioridades de negócios Enterprise: TI verde. 2010. Disponível em: http://www.microsoft.com/brasil/windows/enterprise/business-priorities/green-it.aspx. Acessado em: 15/03/2011.

MINGAY, S. Green IT: the new industry shock wave. Gartner Research. Stanford/EUA, 2007.

MOLLA, A. et al. E-readiness to G-readiness: Developing a green information technology readiness framework. 19th Australasian Conference on Information Systems Proceedings, 2008.

MOLLA, A. Organizational Motivations for Green IT: Exploring Green IT Matrix and Motivation Models. PACIS 2009 Proceedings, 2009.

MONTE, F. USP quer ser referência em TI verde. Computerworld. 2009a. Disponível em: http://computerworld.uol.com.br/gestao/999/12/31/usp-quer-ser-referencia-em-ti-verde. Acesso em 12/01/2012.

MONTE, F. Alog Data Centers reduz consume de energia em 65\% com consolidação de data Center. Computerworld. 2009b. Disponível em:

http://computerworld.uol.com.br/gestao/2009/03/31/alog-data-centers-reduz-consumo-deenergia-em-65-com-consolidacao-de-data-center. Acessado em: 12/01/2012.

MONTE, F. 51\% das empresas brasileiras já implementaram TI Verde. Computerworld. 2009c. Disponível em: http://computerworld.uol.com.br/gestao/2009/08/19/51-das-empresasbrasileiras-ja-implantaram-ti-verde. Acessado em: 20/01/2010.

MURUGESAN, S. Harnessing green IT: Principles and practices. IT Professional, v. 10, n. 1, 2008, p. 24-33.

REAd | Porto Alegre - Edição 77 - N 1 - janeiro/abril 2014 - p. 1-30 
TI Verde: uma análise dos principais benefícios e práticas utilizadas pelas organizações

RASMUSSEN, N. Implementing energy efficient data centres. APC White paper \# 114. Revision 1. 2011. Disponível em: http://www.apcmedia.com/salestools/NRAN6LXSHX_R1_EN.pdf. Acessado em: 25/01/2012.

SARKAR, P.; YOUNG, L. Managerial Attitudes Towards Green IT: An Explorative Study of Policy Drivers, PACIS 2009 Proceedings, 2009.

SILVA, T. TI Verde - um estudo de aplicações e impactos. Monografia de conclusão de curso de Tecnólogo em Informática para Gestão de Negócios, Faculdade de Tecnologia da Zona Leste, São Paulo, SP, Brasil.

SPOSITO, R. TI verde. Info Corporate. 2008. Disponível em:

http://info.abril.com.br/corporate/ti-verde/ti-verde.shtml. Acessado em: 18/12/2009.

THIBODEAU, P. Gartner's Top 10 Strategic Technologies for 2008. Computerworld, 2007.

VANTTINEN, M.; PYHALTO, K. Strategy process as an innovative learning environment, Management Decision, v. 47, n. 5, 2009, p.778-791.

VELTE, T.; VELTE, A.; ELSENPETER, R. Green IT: reduce your information systems environmental impact while adding to the bottom line. New York: McGraw-Hill, 2008.

ZMOGINSKI, F. Google prepara data center em alto mar. Info Online. 2009. Disponível em: http://info.abril.com.br/ti-verde/google-prepara-data-center-em.shtml. Acessado em: $12 / 01 / 2012$.

WATSON, R.; BOUDREAU, M.; CHEN, A. Information systems and environmentally sustainable development: Energy informatics and new directions for the IS community. MISQ, v. 34, n. 1, 2010, p. 23-38.

YURI, F. Quatro exemplos reais de TI verde em grandes empresas brasileiras.

Computerworld. 2009. Disponível em:

http://computerworld.uol.com.br/gestao/2008/04/16/quatro-exemplos-reais-de-ti-verde-emgrandes-empresas-brasileiras. Acessado em: 15/02/2011. 